\title{
Programa Cegonha Carioca: Percepção Das Puérperas A Respeito Da Assistência Pré-Hospitalar Do Enfermeiro
}

\author{
Cegonha Carioca Program: Perception of Puerperos On Nurses' Pre-Hospital Care
}

\author{
Renata Corrêa Bezerra de Araújo ${ }^{1}$ \\ Valdecyr Herdy Alves ${ }^{2}$ \\ Diego Pereira Rodrigues ${ }^{3}$ \\ Ediane de Andrade Ferreira ${ }^{4}$ \\ Enimar de Paula ${ }^{5}$ \\ Márcia Vieira dos Santos ${ }^{6}$
}

\footnotetext{
1 Enfermeira, Mestre em Saúde Materno-Infantil. Municipal do Rio de Janeiro, Rio de Janeiro, Brasil. E-mail: renatacbaraujo@hotmail.com

${ }^{2}$ Enfermeiro, Doutor em Enfermagem. Professor do Departamento Materno-Infantil e Psiquiátrico da Escola de Enfermagem Aurora de Afonso Costa da Universidade Federal Fluminense. Rio de Janeiro, Brasil. E-mail: herdyalves@yahoo.com.br

${ }^{3}$ Enfermeiro, Mestre em Enfermagem.Professor Adjunto do Centro Universitário Anhanguera de Niterói. Rio de Janeiro, Brasil. E-mail:

diego.pereira.rodrigues@gmail.com

4 Enfermeira. Mestre em Saúde Materno-Infantil. Professora Assistente da Universidade Federal do Amapá, AP - Brasil. E-mail: edianesaude@gmail.com

5 Enfermeiro, Especialista em Enfermagem Obstétrica, Prefeitura Municipal do Rio de Janeiro, Rio de Janeiro, Brasil. E-mail: enimar.enfermagem@msn.com

${ }^{6}$ Enfermeira, Mestre em Saúde Materno-Infantil. Secretaria Municipal de Saúde de Itaguaí, Rio de Janeiro, Brasil. E-mail: enfa.marcia@oi.com.br

\begin{tabular}{|c|c|c|}
\hline (c) (1) & Esta obra está lice nciada sob uma Licença Creative Commons Atribution 3.0 . & REVISTA ENFERMAGEM ATUAL | 2018; 86: EDIÇÃO ESPECIAL \\
\hline
\end{tabular}
}




\section{RESUMO}

Objetiva-se analisar as percepções das mulheres acerca da assistência do enfermeiro no atendimento pré-hospitalar do Programa Cegonha Carioca. Estudo descritivo, exploratório, com quartoze puérperas da Maternidade Municipal Mariska Ribeiro, que tiveram contato com o enfermeiro quanto ao módulo Transporte Seguro no Programa Cegonha Carioca. Todas foram submetidas à entrevista semiestruturada individual, transcritas posteriormente e submetidas à análise de conteúdo na modalidade temática. As categorias formadas foram: Acolhimento da enfermagem no cuidado domiciliar à gestante: a construção do vínculo para uma assistência segura; Transporte seguro: expressões das mulheres para o sentimento positivo; A qualidade da ambulância e o transporte seguro; Enfermeiros na assistência pré-hospitalar do Programa Cegonha Carioca: satisfação, agilidade e segurança. Conclui-se que as mulheres reconhecem e valorizam o enfermeiro como integrante do processo do cuidado durante todo o atendimento e assistência ao parto e nascimento.

Palavras-chave: Serviços de saúde materno-infantil; Serviços médicos de emergência; Obstetrícia; Saúde da Mulher.

\section{ABSTRACT}

The objective of this study was to analyze the perceptions of women about the nurses' care in the pre-hospital care of the Cegonha Carioca Program. A descriptive, exploratory study with fourteen mothers of the Municipal Maternity Mariska Ribeiro, who had contact with the nurses about the Safe Transport module in the Cegonha Carioca Program. They were submitted to the individual semi structured interview, later transcribed and submitted to content analysis in the thematic modality. The categories formed were: Nursing care in the home care of the pregnant woman: the construction of the bond for a safe care; Safe transportation: women expressions for positive feeling; Ambulance quality and safe transportation; Nurses in the pre-hospital care of the Cegonha Carioca Program: satisfaction, agility and safety. It is concluded that women recognize and value nurses as part of the care process throughout care and delivery.

Keywords: Maternal-child health services; Emergency medical services; Obstetrics; Women's health. 


\section{INTRODUÇÃO}

O serviço de atendimento pré-hospitalar envolve todas as ações que ocorrem antes da chegada de qualquer paciente ao ambiente hospitalar, podendo influir positivamente nas taxas de morbidade e mortalidade por traumas, violências e intercorrências de saúde. Nesse sentido, uma assistência qualificada durante o transporte e a chegada precoce ao hospital tornase fundamental para que a taxa de sobrevida aumente. ${ }^{(1)}$ Na prática cotidiana do atendimento pré-hospitalar, o serviço estrutura-se a partir de instrumentos tecnológicos e estabelecimento de relações entre os atores, especialmente o atendimento ao paciente. As atividades desenvolvidas caracterizam-se como trabalho coletivo, cujo resultado depende muito da competência e qualificação de cada membro da equipe. $^{(2)} \mathrm{Em}$ espacial, no atendimento de mulheres em situação de processo parturitivo deve haver um sistema integrado para a assistência qualificada do profissional de saúde em prol da segurança e bem estar perinatal.

Os enfermeiros se destacam como peçaschave nos diversos contextos do trabalho em saúde, incluindo no atendimento pré-hospitalar. Esses profissionais têm a responsabilidade técnica sobre o trabalho da equipe de enfermagem e seu trabalho requer competência técnico-científica em permanente atualização. As instituições de saúde têm buscado, ainda, enfermeiros "multiqualificados e multifuncionais" que dominem a linguagem da informática e das máquinas de alta tecnologia, possuam raciocínio rápido, que tenham iniciativa, sejam criativos, competitivos, comunicativos, dominem outros idiomas, além de possuir traço de líder para formar equipes qualificadas. ${ }^{(3)}$

Nessa perspectiva, em março de 2011 foi implantado no Município do Rio de Janeiro o Programa Cegonha Carioca, pioneiro no Brasil, tendo como objetivos erradicar a peregrinação das gestantes por acesso às maternidades, reduzir as taxas de mortalidade materno-infantil e as complicações evitáveis, além de incentivar a realização do pré-natal por meio de um atendimento humanizado e qualificado, como o transporte seguro da gestante. Foi considerada uma proposta inovadora na busca da ampliação e da qualificação do atendimento à gestante, com consequências benéficas para ela e o recémnascido no parto e puerpério. ${ }^{(4)}$

Desse modo, o enfermeiro é o profissional de saúde que desenvolve ações diretas com a mulher no momento do atendimento pelo transporte seguro do Programa Cegonha Carioca. Com a aplicação da sistematização da assistência em enfermagem, faz-se a coleta de informações objetivas e subjetivas; o exame físico obstétrico, com o toque, em relação ao sangramento, tampão mucoso, dilatação e apagamento do colo uterino; palpação obstétrica, verificando o posicionamento e as contrações uterinas; ausculta, e avaliando a viabilidade fetal, para qualquer sofrimento, e possivelmente 
direcionado o transporte para a unidade de referência, para o atendimento especializado. ${ }^{(5)}$ Pois, a enfermagem obstétrica direciona o seu cuidado na parturição como um evento fisiológico, envolvendo emoções e sentimentos, ${ }^{(6)}$ e necessita a mulher estar acompanhada por profissionais capacitados para exercer sua atribuição com capacidade técnica e intelectual, e intervir quando necessário.

Nesse sentido, a Classificação de Risco e o Acolhimento estruturado, que designa em proporcionar o dimensionamento de atendimento, engloba um processo contínuo que, para ser eficiente, deve ocorrer entre 10 a 15 minutos desde a chegada da usuária à maternidade. Deve ser realizado de forma rápida, fundamentado em um instrumento de classificação previamente elaborado. A classificação de risco evolui o fluxo das usuárias atendidas na emergência, proporcionando maior resultado e rapidez nas respostas. A capacitação e a reflexão continuada devem ser buscadas, de modo a aprimorar e manter a padronização de condutas dos enfermeiros e do planejamento de ações que objetivem o aumento da satisfação dos trabalhadores de saúde e das pacientes. ${ }^{(7)}$

A Organização Mundial de Saúde (OMS) destacou a fragmentação do sistema de saúde da América Latina, ${ }^{(8)}$ ressaltando o baixo nível de desempenho e a dificuldade dos usuários de acesso aos mesmos. Assim, objetivando a superação dessa fragmentação, a referida Entidade propôs um modelo de organização para

Esta obra está licenciada sob uma Licença Cre ative Commons Attribution 3.0 . os sistemas de saúde por meio de Redes de Atenção à Saúde, entendendo que elas possibilitariam um conjunto amplo de intervenções preventivas e curativas para a população, a saber: espaços de integração de vários serviços; atenção à saúde contínua ao longo do tempo; integração vertical de diferentes níveis de atenção; vinculação entre a formulação das políticas de saúde e a gestão; e também o trabalho intersetorial. ${ }^{(9)}$

Nesse sentido, é de suma importância as redes de atenção em prol do atendimento préhospitalar às gestantes, que culminam na segurança da paciente e do concepto por meio de recursos para o transporte seguro, e também com o atendimento e a assistência do profissional de saúde para as mulheres já em situação de trabalho de parto, que contribuem para a não ocorrência de situação de peregrinação do anteparto, favorecendo o acesso ao serviço de saúde e a redução de mortalidade perinatal. ${ }^{(10)}$

No contexto do Programa Cegonha Carioca, ocorre uma reconfiguração do atendimento da gestante nos espaços das emergências obstétricas, e de (re)conhecer as influências do Programa sobre a atenção à saúde das gestantes e autonomia dos enfermeiros em sua prática obstétrica, com o seu atendimento direto no transporte seguro. Desse modo, o enfermeiro é uma figura chave desse modelo de atendimento, onde direciona as suas atividades para a segurança para a mulher e seu concepto. Contudo, há uma necessidade de estudos que 
direcionem 0 atendimento pré-hospitalar na atenção obstétrica, visto que em suma os estudos direcionam somente para $\mathrm{o}$ atendimento de emergências clínicas. ${ }^{(5)}$

Desse modo, o estudo objetivou analisar as percepções das mulheres acerca da assistência do enfermeiro no atendimento pré-hospitalar do Programa Cegonha Carioca

\section{MÉTODO}

Estudo com abordagem qualitativa, descritivo, exploratório, realizado na Maternidade Municipal Mariska Ribeiro situada no município do Rio de Janeiro, vinculada ao Programa Cegonha Carioca e integrante da Área Programáticas 5.1 (AP 5-1), que abrange os seguintes bairros: Bangu, Campo dos Afonsos, Deodoro, Jardim Sulacap, Magalhães Bastos, Padre Miguel, Realengo, Senador Camará e Vila Militar.

As participantes da pesquisa foram 14 mulheres atendidas por enfermeiros no módulo transporte seguro da citada maternidade, que atenderam aos critérios de inclusão: ter mais de 18 anos de idade; ter realizado o parto na Maternidade; ser puérpera durante a entrevista; estar no alojamento conjunto; e ter tido pelo menos um contato com o atendimento préhospitalar do Programa Cegonha Carioca. Foram excluídas as puérperas que permaneceram na sala de parto; no centro cirúrgico; que não realizaram pré-natal na rede de Atenção Básica do município; e as que chegaram na maternidade

Esta obra está licenciada sob uma Lcença Oreative Commons Attribution 3.0 . por meios próprios. Foi assegurado o anonimato e o sigilo das informações com a utilização de um código alfanumérico $\left(\mathrm{P}_{1} \ldots \mathrm{P}_{14}\right)$ para cada entrevistada.

O estudo foi aprovado pelo Comitê de Ética em Pesquisa da Faculdade de Medicina da Universidade Federal Fluminense, conforme determina a Resolução 466/2012 do Conselho Nacional de Saúde, que dispõe sobre pesquisa envolvendo seres humanos ${ }^{(11)}$, sob protocolo 1.247.916, e pelo Comitê de Ética da Secretaria Municipal de Saúde do Rio de Janeiro, sob protocolo no 1.474.604/2016.

Como instrumento de coleta de dados, foi utilizado um roteiro de entrevista semiestruturada individual. As entrevistas foram realizadas de junho a dezembro de 2016, e submetidas à transcrição na íntegra pelo pesquisador, tendo em vista a análise de conteúdo na modalidade temática. ${ }^{(12)}$

A partir da questão de pesquisa levantada: Como a mulher compreende a assistência do enfermeiro que atua no atendimento pré hospitalar do Programa Cegonha Carioca?, a analise de conteúdo se fundamentou em três etapas: Na primeira, foi realizada a organização e leitura do material, buscando conhecer a estrutura e as impressões das mensagens dos dados coletados, e assim registrando a unidade de contexto distintas, trechos significativos e categorias. Na segunda etapa, a exploração do material, onde foi aplicado varias (re)leituras do material para 
viabilizar a organização do conteúdo, tendo como objetivo as codificações, decomposição e enumeração do material. $E$, na ultima etapa, na codificação, foram escolhidas as unidades de registro e, a partir destas, a escolha das categorias, todas agrupadas em núcleos temáticos. ${ }^{(12)}$ Desse modo, utilizou-se na fase de unidade de registro, a montagem de um quadro de registro, com a aplicação de colometria, com cores, para a finalidade de auxiliar a organização e agrupamentos das unidades.

As unidades de registro que surgiram no processo de análise foram: o cuidado domiciliar com a gestante; a confiança no processo de cuidado; o acolhimento da enfermagem no cuidado domiciliar; o cuidado de enfermagem como processo de segurança; o sentimento positivo na assistência realizada pelo enfermeiro; o reconhecimento da qualidade da ambulância e seus insumos; satisfação no processo de atendimento na admissão; agilidade no processo de transporte e atendimento; segurança no serviço prestado, permitindo a construção dos seguintes núcleos temáticos: assistência de enfermagem domiciliar com as gestantes; assistência de enfermagem no transporte de gestantes; admissão na maternidade/expressões das mulheres; tudo contribuindo para a construção das seguintes categorias: 1) 0 acolhimento da enfermagem no cuidado domiciliar à gestante: a construção do vínculo para uma assistência segura; 2) Transporte seguro: expressões das mulheres para o sentimento positivo frente à qualidade da ambulância e do transporte seguro; 3) Enfermeiras na assistência pré-hospitalar do Programa Cegonha Carioca: satisfação; agilidade e segurança.

\section{RESULTADOS}

\section{O acolhimento da enfermagem no cuidado} domiciliar à gestante: a construção do vínculo para uma assistência segura

As participantes apontaram para uma relação direta entre o acolhimento domiciliar como parte fundamental para estabelecimento do vínculo com o profissional enfermeiro, conforme os depoimentos a seguir:

Eles chegaram na minha casa, entraram no meu quarto me examinaram. Nossa, foi uma coisa muito legal. A gente liga e eles vêm atender em casa, se você estiver sentindo dor ou alguma coisa assim (P1).

Perfeito! O enfermeiro pediu meu cartão pré-natal, pediu a primeira ultra, fez perguntas, verificou minha pressão, coração do neném, explicaram por que agente ia para maternidade, eu já estava em trabalho de parto. Muito tranqüilo, me acalmou. Me senti acolhida, bem cuidada (P3).

A enfermeira do Cegonha chegou, o atendimento foi bom. Porque ela ficava conversando comigo, me examinou, me explicava tudo, a gente ria e brincava e até 
esqueci da dor um pouco (P13).

As mulheres apontam em seus depoimentos a importância de se estabelecer o vínculo com o enfermeiro, como fator para a garantia da qualidade do atendimento, conforme depoimentos abaixo:

Perguntou tudo direitinho, fez tudo que a enfermeira faz com agente no posto, fez exame do coração do meu filho, não tenho o que reclamar não. Me senti muito segura (P6).

Foi bom. A enfermeira era simpática. Ela me acalmou, falou que aquilo tudo que eu estava sentindo era normal, me ensinou a respirar. Ela falou: respira assim: Cheira uma flor, assopra uma vela, minha respiração estava nervosa. Eu estava sentindo muita contração, ela me ensinou direitinho. Contou as contrações. Me senti um pouco melhor, mas a dor era muito forte (P8).

Ele chegou, foi bem atencioso. Me senti super bem cuidada (P9).

Transporte seguro: expressões das mulheres para o sentimento positivo da qualidade da ambulância e do transporte seguro

As participantes do estudo sinalizaram a satisfação de serem atendidas na ambulância, além de se surpreenderem com a estrutura interna do veículo, como se constata a seguir:
Nunca tinha andado de ambulância, lá dentro tem tudo, a enfermeira me contou que até parto pode acontecer lá, fiquei "boba" de saber $e$ feliz também, risos (P5).

Foi bom e rápido, toda hora me perguntava, está tudo bem com você? Achei a ambulância bem cheia de coisas, até perguntei se algum neném já nasceu ali e o enfermeiro me disse que sim, achei legal! Me senti até melhor, mais segura (P8).

Foi tranquilo. Foi tudo bem. Perguntei para que servia tudo aquilo que tem lá dentro, ele me explicou tudo. Me senti super mais tranqüila (P10).

Identificou-se também o sentimento positivo por serem atendidas pelo enfermeiro no transporte seguro:

É um ambiente bem diferente, mas foi bem tranqüilo $e$ a moça não saiu do meu lado. Como eu me senti? Me senti especial! (P6).

Uma coisa positiva, eu acho que é na ambulância, em si só de ter um veículo que possa nos trazer na maternidade já é algo muito bom. Mas um ponto mais positivo ainda, são as profissionais, os profissionais que estão lá dentro que são muito, eles são muito atenciosos (P14).

Enfermeiros na assistência pré-hospitalar do Programa Cegonha Carioca: satisfação; agilidade e segurança 
A Rede Cegonha foi pioneira em respeitar o acompanhante não só como um direito da mulher, mas também como uma iniciativa para implementação das boas práticas do parto e nascimento. Preconizou a presença do acompanhante em todo o processo parturitivo, visando a tranqüilidade e a segurança da mulher, conforme os seguintes depoimentos:

Eles me colocaram na maca e me colocaram dentro da ambulância, daí a enfermeira do cegonha sentou na cadeira e foi conversando comigo $e$ com meu marido na boa até aqui. Foi tranquilo também (P7).

Cheguei tranqüila aqui, meu marido fez a ficha e eu fiquei esperando o médico me chamar, a enfermeira ficou comigo, depois o médico me chamou e ela foi embora. Muito simpática a moça. Me senti bem, meu marido também gostou muito (P11).

Fiquei tranquila. Eu deitei, ele me prendeu. Ele e minha mãe foram sentados e a gente veio. Fiquei calma (P13).

Estratégia como o acolhimento e a classificação de risco vem se destacando por oferecerem às mulheres maior segurança no que diz respeito à um atendimento eficiente e seguro, como relatado a seguir:

Ah, eles me trouxeram para cá, vim falar com o pessoal daqui e fui logo atendida. Senti bem. Porque eu pensava que ia passar mal e não ia conseguir chegar, mas rapidinho chegamos aqui (P1). Aí quando eu cheguei a bolsa já estourou e foi aquele correcorre, me levaram correndo para a sala de parto e minha mãe foi fazer a ficha. $O$ enfermeiro ficou do meu lado o tempo todo, depois minha mãe chegou e o neném já tinha nascido e correu tudo bem. Fiquei feliz, no fim tudo deu certo (P3).

Aqui é ótimo. Em menos de quinze minutos fui atendida. Logo subi. Gosto muito daqui, é bonito, as pessoas são educadas, toda hora vêem alguém e pergunta: Está tudo bem?, parece particular. Me senti muito bem (P11).

Foi bom também. Muito rápido o atendimento. Eu já conhecia a maternidade, porque vim na visita, falei para meu marido- Amor, vai fazer a ficha, que eu te espero no acolhimento. Gostei de tudo. (P12).

\section{DISCUSSÃO}

Para a melhoria da organização, funcionamento e resolubilidade da rede assistencial na área materno-infantil, foram lançados simultaneamente a Rede Cegonha, em âmbito Federal, e o Programa Cegonha Carioca, no município do Rio de Janeiro, em 28 de março de 2011. O referido programa, por sua vez, busca ampliar e qualificar a assistência prestada às gestantes no município do Rio de Janeiro. É composto de três módulos: pré- natal, transporte e acolhimento. O módulo transporte é 
caracterizado pela disponibilização de serviço de atendimento móvel às parturientes que necessitam de remoção do domicílio para a maternidade. ${ }^{(13)}$ Assim, durante o transporte, deve ser realizado o acolhimento das mulheres no domicílio.

O processo de trabalho, em consonância com a proposta da prática de acolhimento, transformam o ambiente de cuidado de tal forma que o profissional de saúde e a usuária, neste caso a gestante, sentem-se beneficiados. Juntos, eles buscam soluções para os problemas apresentados, considerando as queixas e a organização do serviço. ${ }^{(14)}$

Assim, o ato de acolher na área de saúde é, portanto, ao mesmo tempo, uma diretriz ética/política no modelo de produção da saúde e uma ferramenta tecnológica avançada no desenvolvimento da escuta, garantia ao acesso e à formação do vínculo. O acolhimento é um dispositivo que possibilita o encontro e, dessa forma, reforça o vínculo. Permite, ainda, a análise do processo de saúde com foco nas relações por ele estabelecidas, o que leva ao reconhecimento do usuário como agente de participação no processo de construção e desenvolvimento da saúde. ${ }^{(15)}$

A enfermagem possui características que se aproximam dos princípios do acolhimento. Em sua formação, o enfermeiro entende o cuidado como uma necessidade humana básica, e disso advêm características marcantes como a escuta sensível, aberta ao dialogo, para a criação de

Esta obra está licenciada sob uma Licença Creative Commons Attribution 3.0 . vínculo entre esse profissional e a usuária do serviço, sem preconceitos, buscando sempre a melhor resolutividade para o problema exposto, sensibilidade para compreender o outro, boa comunicação e arguição. ${ }^{(16)}$

Não é demais lembrar que o vínculo estabelecido por meio do acolhimento está ligado ao ato de cuidar. Sendo assim, o profissional de saúde, ao se aproximar da realidade da população sob sua responsabilidade, deve levar em consideração a subjetividade de cada família, pois cada uma lida com a saúde e com o agravo de forma distinta. Diante disso, a maneira como a equipe atua dependerá dos aspectos culturais e dos comportamentos de cada pessoa e da comunidade, respeitando-se todos os seus aspectos. Quando isso ocorre, a aceitação das propostas de cuidados à saúde se dá por meio da confiança nos profissionais e, assim, vai se constituindo o vínculo na prática diária da atenção à saúde. ${ }^{(17)}$

A escuta também é uma estratégia utilizada pelos profissionais de saúde e faz parte do processo do acolhimento, pois desperta no usuário um sentimento de que ele é único, elevando a confiança no profissional, facilitando a criação de vínculo. ${ }^{(18)}$ Nesse sentido, as recomendações do Programa de Humanização do Parto e Nascimento estabelecem que a mulher tem direito ao atendimento digno e de qualidade que requer uma escuta sensível, imprescindível e de suma importância para estabelecer o cuidado a ser oferecido no transporte seguro. ${ }^{(5)}$ Visto que, 
o acolhimento mostra como processo de escuta da mulher, envolvendo a subjetividade do sujeito, expressando em processo de satisfação perante o cuidado realizado, por meio de desfrutar esse espaço de abertura, colocando seus medos, angustias e dúvidas. ${ }^{(19)}$ Desse modo, o acolhimento da enfermagem no domicílio com o transporte seguro permite esse processo de criação de vínculo, e favorecendo a confiança da mulher e de sua satisfação do cuidado realizado, perpetuando um cuidado com segurança.

O atendimento, portanto, deve se organizar em redes de atenção à saúde, que são organizações poliárquicas de conjuntos de serviços em que todos os pontos de atenção à saúde são igualmente importantes, e se relacionam horizontalmente. Representam um continuum de atenção nos níveis primários, secundários e terciário, sendo vinculados entre si por uma missão única, objetivos comuns e uma ação cooperativa e independente, aspectos que permitem ofertar uma atenção contínua e integral a determinada população. ${ }^{(20)}$ Assim, com um sistema integrado, permite um atendimento eficaz e resolutivo para a saúde perinatal, e as mulheres do estudo tiveram uma excelente perspectiva do cuidado realizado pelo transporte seguro.

$\mathrm{O}$ atendimento pré-hospitalar necessita evoluir quanto ao transporte utilizado, como da satisfação, visto que em um estudo apontou que a satisfação está relacionado com a rapidez e qualidade do serviço ofertado, que detém

Esta obra está licenciada sob uma Lcença Oreative Commons Attribution 3.0 . infraestrutura satisfatória para um atendimento de qualidade, onde $52 \%$ afirmou que receberam um bom atendimento, com a satisfação dos usuários do serviço, e como $90 \%$ com o tempo adequado de chegada ao local para o atendimento de uma emergência. ${ }^{(21)}$ Desse modo, a infraestrutura é um dos fatores considerados mais relevantes para a satisfação do paciente, do que propriamente sua cura. $\mathrm{O}$ ambiente deve abranger limpeza, equipamentos, mobílias apropriadas e ventilação suficiente, para que um atendimento apropriado efetive uma atenção com acesso digno, acolhedor e confortável. ${ }^{(22)}$

Assim, pudemos perceber através dos depoimentos das participantes, o sentimento de segurança em relação ao transporte seguro ofertado pelo Programa Cegonha Carioca, promovendo a sua satisfação e sentimentos positivos do cuidado oferecido. No Brasil, o Ministério da Saúde lançou o Programa Nacional de Segurança do Paciente ${ }^{(23)}$, o que contribuiu muito na qualidade do cuidado. Nesse sentido, torna-se necessária a observância das suas diretrizes para o processo parturitivo, com medidas em prol da mulher, pois a sua segurança favorece a ocorrência de desfechos positivos para o processo do parto e nascimento. ${ }^{(23)} E$ com essa perspectiva, o cuidado de enfermagem com as mulheres torna-se mais positivo.

$\mathrm{O}$ respeito ao direito ao acompanhante contribui para $\mathrm{o}$ processo de confiança e satisfação da usuária, fazendo com que a mulher se sinta valorizada e segura nesse momento 
ímpar da sua vida. O impedimento da presença de um acompanhante durante o trabalho de parto viola o direito da mulher como cidadã e também a própria capacidade de autonomia, direito de escolha de optar pela presença ou não de um acompanhante, da pessoa que ela deseja que esteja ao seu lado nesse momento. ${ }^{(24)}$ Visto que a falta da presença do acompanhante, que favorece a sentimentos negativos, e a perspectiva do direito da mulher, culmina na sua insatisfação e insegurança da mulher e do concepto. ${ }^{(25)}$

Nos depoimentos das mulheres, foi evidenciado $\mathrm{o}$ atendimento tendo por base a escuta ativa e o bom desempenho profissional, que propiciaram o vínculo do binômio usuáriaserviço de saúde. Esse vínculo aperfeiçoa o processo de assistência e proporciona aos profissionais a oportunidade de conhecer as necessidades das gestantes, permitindo ainda que as usuárias do serviço de saúde aumentem sua autonomia e satisfação, principalmente quanto ao direito ao acompanhante de livre escolha.

Assim, o enfermeiro é o profissional qualificado para fazer a classificação de risco. 0 "cuidar humanizado" reflete a concepção de qualidade, sendo o cuidador percebido como alguém dinâmico, capaz de acolher, refletir, reconhecer e desempenhar uma assistência com competência e sensibilidade. ${ }^{(26)}$

\section{CONCLUSÕES}

Esta obra está licenciada sob uma Lcença Cre ative Commons Attibution 3.0 .
Neste estudo, foi possível identificar que as mulheres reconhecem e valorizam o trabalho do enfermeiro que atua no módulo Transporte Seguro do Programa Cegonha Carioca. O atendimento domiciliar inicia-se por meio da valorização. $O$ enfermeiro valoriza a demanda e enfatiza a singularidade da mulher, começando naquele momento a construção do vínculo usuária-profissional, gerando sentimentos positivos e de satisfação nas mulheres.

Constatou-se uma relação direta no acolhimento domiciliar com as mulheres, como parte fundamental para o estabelecimento do vínculo com o profissional enfermeiro, gerando com isso, sentimentos de segurança, proteção e tranquilidade, propiciando um desfecho positivo para o vivenciar esse momento.

Assim, o Programa Cegonha Carioca encontra-se em consonância com as bases políticas e filosóficas do Sistema Único de Saúde (SUS), principalmente no que diz respeito à universalidade, integralidade e equidade, uma vez que o atendimento humanizado é direcionado para todas as mulheres no período gravídico e puerperal. Ademais, e considerando que a assistência tem início na atenção primária a partir da descoberta da gestação, esta constatação favorece o pré-natal significando o começo da vinculação da usuária ao Programa Cegonha Carioca que, posteriormente, terá acesso ao transporte seguro e, principalmente, ao encaminhamento à maternidade de referência para a realização do seu parto. 
O acolhimento é ressaltado nos depoimentos das gestantes no atendimento domiciliar feito pelo enfermeiro do transporte seguro do Programa Cegonha Carioca, realizado de forma eficaz, o que claramente obteve a satisfação das usuárias do serviço. Assim, o acolhimento é visto como responsável pela aliança do profissional de saúde com a gestante, favorecendo um atendimento integral por parte do enfermeiro, e participativo por parte da gestante.

No que tange ao profissional enfermeiro do transporte seguro, foi percebido que esse profissional tem as condições necessárias para classificar e sistematizar sua assistência, possibilitando assim um cuidado de qualidade e com desfecho positivo para a gestante e seu bebê. Portanto, é imperativo que os profissionais de enfermagem se aproximem da prática clínica, valorizando o acolhimento e o vínculo com a usuária do serviço, produzindo cuidados resolutivos.

Torna-se necessário que novos estudos sejam realizados quanto à questão do transporte seguro, com ênfase na satisfação das mulheres, possibilitando a criação de subsídios para aprimorar as ações dos enfermeiros, tornando-as mais eficazes para a segurança do processo de nascimento em todo o território brasileiro.

Há necessidade de avaliação do módulo transporte, principalmente nos municípios que estão alinhados com a Rede Cegonha, para que possa ser um processo contínuo em prol da

Esta obra está licenciada sob uma Lcença Oreative Commons Attribution 3.0 . segurança da mulher, promovendo pesquisa quanto à eficácia do módulo transporte e dos gestores e profissionais envolvidos.

\section{REFERÊNCIAS}

1. Adão RS, Santos MR. A atuação do enfermeiro no atendimento pré-hospitalar móvel. REME Rev Min Enferm. 2012; 16(4): 601-8.

2. Pereira WAP, Lima MADS. O trabalho em equipe no atendimento pré-hospitalar à vítima de acidente de transito. Rev Esc Enferm USP. 2009; 43(2): 320-7.

3. Luchtemberg MN, Pires DEP. Enfermeiros do Serviço de Atendimento Móvel de Urgência: perfil e atividades desenvolvidas. Rev Bras Enferm. 2016; 69(2): 213-20.

4. Ministério da Saúde (Br). Política Nacional de Atenção Integral à Saúde da Mulher: Princípios e Diretrizes. 2a impressão. Brasília: Ministério da Saúde; 2011.

5. Araújo RCB. A percepção da puerpera acerca da assistência do enfermeiro no atendimento pré hospitalar no programa cegonha carioca [dissertação]. Rio de Janeiro: Universidade Federal Fluminense; 2017.

6. Fujita JALM, Nascimento PL, Shimo AKK. O uso da música na parturição: revisão integrativa. Rev Enferm atual. 2015; 72(1): 23-9.

7. Lopes JB. Enfermeiro na classificação de risco em um serviço de emergencia: revisão integrativa [Monografia]. Rio Grande do Sul: Universidade Federal do Rio grande do Sul; 2011.

8. Organização Mundial de Saúde. Redes integradas de servicios de salud basadas en la atención primaria de salud. Washington: Organização Mundial de Saúde; 2009. 
9. Di Giovanni M. Rede cegonha: da concepção à implantação [Monografia]. Brasília: Escola Nacional de Administração Pública; 2013.

10. Rodrigues DP, Alves VH, Penna LHG, Pereira AV, Branco MBLR, Silva LA. A peregrinação no período reprodutivo: uma violência no campo obstétrico. Esc Anna Nery. 2015; 19(4): 61420.

11. Ministério da Saúde (BR). Conselho Nacional de Saúde. Diretrizes e normas regulamentadoras de pesquisa envolvendo seres humanos. Resolução n. 466, de 12 de dezembro de 2012. Brasília: Ministério da Saúde; 2012.

12. Bardin, L. Análise de Conteúdo. São Paulo: Edições 70; 2011.

13. Progianti JM, Pereira ALF, Sé CCS. A prática das enfermeiras obstétricas nas emergências vinculadas ao Programa Cegonha Carioca. Rev Enferm UERJ. 2014; 22(6): 742-7.

14. Scholze AS, Junior Duarte CF, Silva YF. Trabalho em saúde e a implatação do acolhimento na atenção primária à saúde: afeto, empatia ou alteridade? Interface (botucatu). 2009; 13(3): 404-7.

15. Gomes MCPA, Pinheiro R. Acolhimento e vínculo: Acolhimento e vínculo: práticas de Acolhimento e vínculo: integralidade na gestão do cuidado em saúde em grandes centros urbanos. Interface (botucatu). 2009; 9(17): 2456-8.

16. Gonçalves ITJP, Souza KV, Amaral MA, Oliveira ARS, Ferreira WFC. Prática do acolhimento na assistência pré-natal: limites, potencialidades e contribuições da enfermagem. RENE. 2013; 14(3): 620-9.

17. Viegas SMF, Penna CMM. O vínculo como diretriz para a construção da integralidade na estratégia saúde da família. RENE. 2012; 13(2): 375-85.

18. Monteiro MM, Figueiredo VP, Machado MFAS. Formação do vínculo na implantação do Programa Saúde da Família numa Unidade Básica de Saúde. Rev esc enferm USP. 2009; 43(2): 358-64.

19. Arruda C, Silva DMGV. Acolhimento e vínculo na humanização do cuidado de enfermagem às pessoas com diabetes mellitus. Rev Bras Enferm. 2012; 65(5): 758-66.

20. Mendes EV. As redes de atenção à saúde. Brasília: Organização Mundial de Saúde; 2010.

21. Ferreira AM, Nobre JOC, Oliveira LFM, medeiros SC, Davim RB, Alves ESRC. Serviço de atendimento móvel de urgência: satisfação de usuários. Rev enferm UFPE on line. 2017; 11(10): 3718-24.

22. Lima CA, Santos BTP, Andrade DLB, Barbosa FA, Costa FM, Carneiro JA. Qualidade dos prontos-socorros e prontos-atendimentos: a satisfação dos usuários. Einstein. 2015; 13(4): 587-93.

23. Ministério da Saúde (BR). Portaria no 529, institui o Programa Nacional de Segurança do Paciente (PNSP). Brasília: Ministério da Saúde; 2013.

24. Milbrath VM, Amestoy SC, Soares DC, Siqueira $\mathrm{HCH}$. Vivências maternas sobre a assistência recebida no processo de parturição. Esc Anna Nery. 2010; 14(2): 4627.

25. Rodrigues DP, Alves VH, Penna LHG, Pereira AV, Branco MBLR, Souza RMP. O descumprimento da lei do acompanhante como agravo à saúde obstétrica. Texto \& Contexto Enferm. 2017; 26(3): 1-10. 
26. Souza CC, Toledo AD, Tadeu LFR, Chianca TCM. Classificação de risco em prontosocorro: concordância entre um protocolo institucional brasileiro e Manchester. Rev latino-am enferm. 2011; 19(1): 26-33. 